\title{
Synthesis and Characterization of Conjugated Pyridine-( $N$-diphenylamino) Acrylonitrile Derivatives: Photophysical Properties
}

\author{
M. Judith Percino (Corresponding author) \\ Lab de Polímeros, Centro de Química, Instituto de Ciencias, Universidad Autónoma de Puebla \\ Complejo de Ciencias, ICUAP Edif. 103F, 22 Sur y san Claudio, CP 72570, Puebla, México \\ Tel: 52-222-229-5500 ext. 7285 E-mail: judith.percino@correo.buap.mx
}

Víctor M. Chapela, Margarita Cerón, M. Eugenia Castro, Guillermo Soriano-Moro \& Enrique Pérez-Gutiérrez

Lab de Polímeros, Centro de Química, Instituto de Ciencias, Universidad Autónoma de Puebla

Complejo de Ciencias, ICUAP Edif. 103F, 22 Sur y san Claudio, CP 72570, Puebla, México

Tel: 52-222-229-5500 ext.7299 E-mail: victor.chapela@correo.buap.mx;

margarita.ceron@correo.buap.mx; mareug.castro@gmail.com; jesus.soriano@correo.buap.mx; cuper_enrique@msn.com

Francisco Meléndez-Bustamante

LabQT, Centro de Investigación-Dpto. de Fisicoquímica, Facultad de Ciencias Químicas

Universidad Autónoma de Puebla, Edif. 139, 14 Sur y San Claudio

Ciudad Universitaria, CP 72570, Puebla, México

E-mail: francisco.melendez@correo.buap.mx

Received: December 21, $2011 \quad$ Accepted: January 5, $2012 \quad$ Published: April 1, 2012

doi:10.5539/jmsr.v1n2p181 URL: http://dx.doi.org/10.5539/jmsr.v1n2p181

The authors would like to acknowledge VIEP-BUAP for financial support and M. C. Vladimir Carranza for assistance with the EI mass spectrometry.

\begin{abstract}
We have synthesized four novel highly conjugated and fluorescent compounds, 2-(phenyl)-3-(4-diphenylaminophenyl) acrylonitrile (I), 2-(2'-pyridyl)-3-(4-diphenylamino-phenyl) acrylonitrile (II), 2-(3'-pyridyl)-3-(4-diphenylaminophenyl) acrylonitrile III) and 2-(4'-pyridyl)-3-(4- diphenylaminophenyl) acrylonitrile (IV) by the Knoevenagel condensation. In solution, the UV-vis spectra showed two maxima for each compound, one at $\sim 296-300 \mathrm{~nm}$ and the other at $\sim 403-428 \mathrm{~nm}$. The compounds showed fluorescence emission in $\mathrm{CHCl}_{3}$ solution as well as in the state solid. The fluorescence quantum yield for the compounds in powder form showed values ranging from 0.07-0.11. Structures were confirmed with IR, MS, and NMR spectroscopy. Molar coefficient absorption, absorbance, fluorescence emission spectra and fluorescence quantum yield $\left(\Phi_{\mathrm{f}}\right)$ were compared to evaluate the effects of the diphenylamino-substituents and the position of nitrogen on the electronic properties of phenylpyridylacrylonitriles compounds.
\end{abstract}

Keywords: Conjugated compounds, Cyano derivatives, Optical properties, Fluorescent compounds, Powder fluorescence quantum yield, $N$-diphenylphenyl derivatives

\section{Introduction}

Low molecular weight and oligomeric organic compounds with optical or electrical properties have been widely used as dyes in organic electronic devices, including organic light emitting diodes (OLEDs), solar cells, organic 
semiconductor lasers, etc. (Gondek, et al., 2008; Patra, et al., 2002; Yu, et al., 1995; Shaheen, et al., 2001; Tessler, Denton \& Friend, 1996; Samuel \& Turnbull, 2007). Typically, these dyes have a donor-acceptor structure that controls their photophysical properties (Patra, et al., 2002; Zhou, et al., 2008; Adès, et al., 2000). Aromatic amines are among the most important derivatives as materials for hole transport in nanodevices (Pai, Yanus \& Stolka, 1984; Naito \& Miura, 1993; Okutsu, et al., 1997; Thelakkat, et al., 1999; Yakushchenko, et al., 1999; Strzelec, et al., 2001; Jiang, et al., 2002; Loy, Koene \& Thompson, 2002; Xin, et al., 2002; Chen, et al., 2003; Satoh, et al., 2003; Salbeck, 1996; Strohriegl \& Grazulevicius, 2002), and have been used in a wide range of structures, either as separate layers (Salbeck, 1996; Friend, 1999) or covalently attached to light emitting layers (Loy, Koene \& Thompson, 2002; Redecker, et al., 1999; Miteva, et al., 2001; Ego. et al, 2002). In addition, aromatic amines have been tested as blue emitters in organic LEDs (Tong, et al., 2004) and as components of electroluminescent bipolar devices (Justin Thomas, et al., 2002), while arylamines have been used in applications such as antioxidants (Tong, et al., 2001; Esteves, et al., 2001). Triphenylamines, with their characteristic propeller starburst molecular structure, have been widely used in opto- and electroactive materials due to their good electro-donating and transporting capabilities (Ning \& Tian, 2009; Chen, et al., 2009; Zhang, et al., 2009). On the other hand, cyano-substituted compounds, with high electron affinities, show good optical and electrical properties. Molecules with the electron-withdrawing cyano group on the central phenylene ring are strongly fluorescent (Pond, et al., 2002), In particular, some cyano-substituted compounds have been reported to show unique enhanced emission rather than fluorescence quenching in the solid state (Wang, et al., 2011).

Also, poly (phenylenevinylene) compounds (low molecular weight and polymers) are of great interest because they belong to the family of organic materials that possess strong $\pi$-electron conjugation; i.e., they extend electron delocalization. Particularly, the synthesis, structure and photophysical behavior of the trans isomers of 4-( $N$-phenylamino) stilbene have been reported by Yang et al. (2002) A comparison of their results with data for 4-aminostilbene and 4- $N, N$-dimethylaminostilbene indicated that introduction of $N$-phenyl substituents to 4-aminostilbenes led to a more planar ground-state geometry about the nitrogen atom, a red shift of the absorption and fluorescence spectra, and a less distorted structure with a larger charge-transfer character for the fluorescent excited state. Consequently, the $N$-phenyl derivatives showed low photoisomerization quantum yields and high fluorescence quantum yields at room temperature. These investigators described the $N$-phenyl substituted effect as an "amino conjugation effect."

In addition, the high electron affinity of pyridine makes it an important electron-acceptor group. Dailey et al. described the poly(2,5-pyridinediyl) (PPY) moiety as an efficient electron transport layer in bilayer polymeric LEDs. The OLEDs with a PPY layer exhibited external quantum efficiency 60 times greater than that of similar devices without a PPY layer (Dailey, et al., 1998). Epstein et al. described poly (p-pyridine)- and poly(p-pyridylvinylene)-based polymers as emissive layers in light emitting devices (Epstein, et al., 1996).

Finally, the route of synthesis is an important factor to obtain the desired dye structures for a specific application. Some dyes with donor-acceptor structures have been formed in a Heck coupling reaction with palladium-catalysis (Patra, et al., 2002), while others have been formed in the Knoevenagel condensation (Knoevenagel, 1896). Our group previously has synthesized different conjugated compounds with the Knoevenagel condensation, without any catalyst and under solvent-free conditions (Percino, et al., 2007, 2008, 2006, 2010). This method was successfully used to synthesize $\alpha, \beta$-diphenylacrylonitrile, $\alpha$-(2-pyridyl)- $\beta$-(phenyl) acrylonitrile, $\alpha$-(3-pyridyl) - $\beta$-(phenyl)-acrylonitrile, $\alpha$-(phenyl- $\beta$-(2-pyridyl)acrylonitrile, 1,4-bis[1-(2-cyano-2-phenyl)vinyl] -benzene, 1,4-bis[1-(2-cyano-2'-pyridyl)vinyl]benzene and 1,4-bis[1-(2-cyano-3-pyridyl)-vinyl]benzene (Percino, et al., 2010). A series of $E$-isomers of 3-(4-substituted phenyl)-2-arylacrylonitriles (aryl, phenyl or pyridyl) were also prepared. Compounds with chloro-, fluoro-, or dimethylamino substituted aryls and with cyano groups attached to the double bond of acrylonitrile have been synthesized (Percino, et al., 2011). Recently, three novel acrylonitrile derivatives modified with the $N$-ethyl-3-carbazolecarboxaldehyde group to form a D- $\pi$-A structure have been reported (Pérez-Gutiérrez, 2011). These compounds were 2-(2'-pyridyl)-3-( $N$-ethyl-(3'-carbazolyl))acrylonitrile, (2-(3'-pyridyl)-3-( $N$-ethyl-(3'-carbazolyl))acrylonitrile, $\quad$ and $\quad 2$-(4-pyridyl)-3-( $N$-ethyl-(3'-carbazolyl))acrylonitrile. These three compounds showed UV-vis absorption wavelength maxima in solution at 380, 378, and $396 \mathrm{~nm}$, respectively, whereas in the solid state their absorption maxima $\left(\lambda_{\max }\right)$ were observed at 398,390 , and 442 $\mathrm{nm}$, respectively. The fluorescence emission maxima for these compounds were observed at 540, 540 and $604 \mathrm{~nm}$, respectively.

The aim of the present study was to synthesize fluorescent compounds that exhibit a strong emission which could be correlated to the structural properties of the molecules. We have prepared as series of $\mathrm{N}, \mathrm{N}$-diphenylaminophenylpyridineacrylonitrile compounds that exhibited fluorescence in the solid state as well as in solution. We have attempted to relate the intensities and positions of the emission bands as well as their quantum 
yields to the nature of the substituent on the structure, i. e., the -CN substituent on the vinylene moiety of the compound or the position of the $\mathrm{N}$ atom on the pyridine ring. However, we also considered that these interesting properties could be caused by the presence of the $-\mathrm{N}(\mathrm{Ph})_{2}$ group which confers to the structures a high degree of conjugation. Each compound (Scheme 1) reported in the present work was characterized by IR, ${ }^{1} \mathrm{H}-\mathrm{NMR}$, MS, $\mathrm{UV}-\mathrm{Vis}$, fluorescence spectroscopy and fluorescence quantum yield $\left(\Phi_{\mathrm{f}}\right)$.

\section{Experimental Section}

\subsection{Materials and Instrumentation}

Phenylacetonitrile, 2-pyridylacetonitrile, 3-pyridylacetonitrile, hydrochloride 4-pyridylacetonitrile and $p$-diphenylaminophenylcarboxaldehyde were acquired from Aldrich Chemical Co. and were purified before use. Melting points were measured with an SEV $\left(0-300{ }^{\circ} \mathrm{C}\right)$ apparatus and were reported as uncorrected values. IR spectra of the products were recorded on a Vertex (model 70, Bruker Optics, Germany) 750 FT-IR spectrophotometer by attenuated total reflectance (ATR). ${ }^{1} \mathrm{H}$ NMR and ${ }^{13} \mathrm{C}$ NMR spectra were obtained in $\mathrm{CDCl}_{3}$ and DMSO- $d_{6}$ on a Varian $400 \mathrm{MHz}$ NMR spectrometer (Varian NMR, Walnut Creek, CA). The electron ionization (EI) spectra were acquired on a Jeol MStation 700-D mass spectrometer (Jeol USA, Peabody, MA). The UV-vis and fluorescence spectra were acquired with a Spectrometer SD2000 (Ocean Optics, Dunedin, FL). For compounds in solution, absorption was measured at room temperature in $\mathrm{CHCl}_{3}$. For compounds in solid state, absorption was measured using pellets prepared with KBr. A UV/Vis DT $1000 \mathrm{CE}$ light source (Analytical Instrument Systems, Inc., Flemington, NJ) was used for measuring absorption. The molar absorption coefficient ( $\varepsilon$ ) was calculated according to the Beer-Lambert law $\mathrm{A}=\varepsilon \mathrm{cl}$ (Gordon \& Ford, 1972). The excitation source for measuring the fluorescence and fluorescence quantum yield $\left(\Phi_{\mathrm{f}}\right)$ was a laser diode at a wavelength of $405 \mathrm{~nm}$. The $\Phi_{\mathrm{f}}$ was measured on compounds in powder form with the experimental setup described by De Mello et al. (1997) and these values were compared with the quantum yield of $\mathrm{Alq}_{3}$ as a reference.

\subsection{Syntheses of Compounds I-IV}

The synthesis of compounds I to IV was performed according to Scheme 1. Compounds I to IV were obtained by mixing 1:1:1 molar amounts of arylacetonitrile, $p$-(dimethylaminophenyl) aldehyde and piperidine. Piperidine acted as both catalyst and solvent. All reactions were reflux reactions, conducted in the absence of another solvent at $100{ }^{\circ} \mathrm{C}$ with reaction times of 24-36 h. At all times during the reaction, the mixtures appeared oily with a brown to red color. All mixtures were neutralized with a solution of $\mathrm{HCl}(2 \mathrm{~N})$ to precipitate the products as powders and afterwards, were washed with $\mathrm{H}_{2} \mathrm{O}$. The products were purified by recrystallization with a solvent mixture of methanol: hexane (3:1) for I and III, ethyl acetate:hexane (2:1) for II and hexane:dichloromethane (4:1) for IV. All compounds were characterized by IR, ${ }^{1} \mathrm{H}-\mathrm{NMR}$, EI mass spectrometry, UV, fluorescence spectroscopy, and fluorescence quantum yield $\left(\Phi_{\mathrm{f}}\right)$.

\section{Results and Discussion}

The synthesis of compounds I to IV was performed according to Scheme 1, and following a similar procedure recently reported for dimethylaminophenylacrylonitrile derivatives [2-(phenyl)-3-(4-dimethylaminophenyl) acrylonitrile, 2-(2'-pyridyl)-3-(4-dimethylaminophenyl)acrylonitrile, 2-(3'-pyridyl)-3-(4-dimethylamino-phenyl) -acrylonitrile, and 2-(4'-pyridyl)-3-(4-dimethylaminophenyl)acrylonitrile] (Percino, et al., 2011). The temperature was constant at $100{ }^{\circ} \mathrm{C}$ for all reactions. The reaction times for the syntheses varied from $24-36 \mathrm{~h}$, depending on the phenyl- and ortho-, meta-, and para- positions of the pyridine (Table 1). The yields in the present syntheses were smaller than those recently reported (Percino, et al., 2011), indicating that the aromatic aldehyde may play a more important role than the cyano methylene group $\left(-\mathrm{CH}_{2} \mathrm{CN}\right)$. The compounds were only obtained in the presence the piperidine catalyst which could be explained by the low reactivity of the $-\mathrm{COH}$ group through the $-\mathrm{N}(\mathrm{Ph})_{2}$ or $-\mathrm{N}\left(\mathrm{CH}_{3}\right)_{2}$ moeities, which are strong electron donating groups. Also regardless of the position of the $\mathrm{N}$ on the pyridine ring, we observed similar reactivity of the reagents and similar yields. A lower reactivity was observed for the 3 or meta position, as was expected.

\subsection{FT-IR and NMR Characterization.}

For newly synthesized compounds I-IV, signals for a conjugated double bond $v(-\mathrm{C}=\mathrm{C}-)$ of an alkene at $\sim 1625$

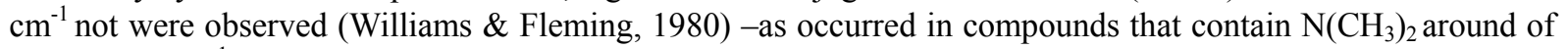
1613-1610 $\mathrm{cm}^{-1}$ (Percino, et al., 2011) - and this behavior could be attributed the overlap of the signals arising from the $v(-\mathrm{C}=\mathrm{C}-)$ from the aromatic and pyridine rings. This evidence may indicate that the electrons in the compounds exhibit a higher extent of delocalization. The electrons from $\pi$ bonds are delocalized or spread out over the whole system (acting as a group of interacting conjugated atoms) (Table 2). The bands at 2209, 2204, 2212 and $2209 \mathrm{~cm}^{-1}$ were assigned to the $-\mathrm{CN}$ group and are an indication that even with the $-\mathrm{C} \equiv \mathrm{N}$ attached to 
the alkene double bond, the presence of the $-\mathrm{N}(\mathrm{Ph})_{2}$ in the $p$-position induced a strong conjugation. Also, the band around of $758 \mathrm{~cm}^{-1}$ for I-IV was assigned to a $\delta(\mathrm{C}-\mathrm{H})$ vibration from a double bond in each compound.

The ${ }^{1} \mathrm{H}-\mathrm{NMR}$ data in $\mathrm{CD}_{3} \mathrm{Cl}$ solution showed a general deshielding effect on the protons of the compounds (Table 2). Thus the proton H-3 for compounds I-IV appears at 7.297, 8.429, 7.524, and 7.809 ppm (7.54 ppm corresponds to the chemical shift of a proton in a double bond) (Xie, et al., 2005). The same protons associated with the $-\mathrm{N}\left(\mathrm{CH}_{3}\right)_{2}$ substituent were reported at 7.41, 8.33, 7.43 and $7.01 \mathrm{ppm}$ for the respective phenyl, ortho, meta and para locations of the nitrogen atom in pyridine, indicating a moderate deshielding effect on the protons due to the presence of $-\mathrm{N}\left(\mathrm{CH}_{3}\right)_{2}$ rather than $-\mathrm{N}(\mathrm{Ph})_{2}$ as well as an effect related to the presence of $-\mathrm{CN}$ group.

\subsection{One Photon Absorption and Emission}

The UV absorption spectra of compounds I-IV both in liquid $\mathrm{CHCl}_{3}$ and in the solid state (Figure 1a and $1 \mathrm{~b}$, respectively) showed two major absorption bands: one at $\lambda_{\max } 296-301 \mathrm{~nm}$, corresponding to the $\mathrm{n} \rightarrow \pi^{*}$ transition for the electron transfer from the amine moieties to the acrylonitrile in the main 4-diphenylaminophenyl chromophores, and a second absorption band with $\lambda_{\max }$ at $416-427 \mathrm{~nm}$. The longer wavelength bands may be assigned to $\pi-\pi^{*}$ transition of the conjugated $R R C=C_{2} R_{2}$ segments (Gordon, 1972). This longer wavelength chromophore for the new compounds was red shifted, as compared to similar previously synthesized compounds that contained the $\mathrm{N}\left(\mathrm{CH}_{3}\right)_{2}$ group ( $\lambda_{\max }$ at 381-406 nm) (Scheme 2 and Figure 2). The extended delocalization of the nitrogen pair onto the additional two phenyl groups from $-\mathrm{N}(\mathrm{Ph})_{2}$ accounts for the red shift of the absorption band [49]. The molar absorptivity coefficient $(\varepsilon)$ is an intrinsic property of a species and provides a useful point of comparison for different compounds. Compounds I-IV displayed values of $\varepsilon$ that exceeded 10,000 (Figure 1c), and the extinction coefficients of the newly synthesized compounds were also higher those of previously synthesized analogues bearing the $-\mathrm{N}\left(\mathrm{CH}_{3}\right)_{2}$ group (Figure $2 \mathrm{~b}$ ). The short wavelength bands at $\sim 300 \mathrm{~nm}$ also showed values of $\varepsilon>2 \times 10^{4}$ that exceeded the corresponding values of $\varepsilon$ for the compounds with the $-\mathrm{N}\left(\mathrm{CH}_{3}\right)_{2}$. Furthermore, we detected a small bathochromic effect between isomers $(\mathbf{I}=\mathbf{I I}<\mathbf{I I I}=\mathbf{I V})$ that can be attributed to the position of the nitrogen atom in the ring.

\subsection{Emission Characterization}

The normalized absorption (UV) and photoluminescence (PL) emission spectra of I-IV in chloroform solution are shown in Figure 3. Compounds I-IV were highly fluorescent both in solution and in the solid state. The photoluminescence spectra of the molecules in chloroform as well as in the solid state were characterized by strong emissions with maxima at 521-530 nm for the all compounds whereas in the solid state, the emission maxima appeared at 506 for I, 535 for II and III, and $542 \mathrm{~nm}$ for IV. In both solution and in the solid state, the wavelength of emission corresponded to green light. The emission band of compound $\mathbf{I}$ is blue-shifted with respect to that of II-IV (Figure 4). This effect could be due to the absence of the pyridine moiety in compound I. All compounds displayed considerable Stokes shifts, indicating a substantial geometrical difference between the ground and excited states. The fluorescence quantum yield values in the solids were of 0.07, 0.08, 0.11 and 0.09 for I-IV, respectively. We also compared the fluorescence emissions of compounds I-IV with the fluorescence of compounds of the recently reported $-\mathrm{N}\left(\mathrm{CH}_{3}\right)_{2}$ analogues which only exhibit PL in the solid state (Figure 5) (Percino, 2008). The dimethylamino derivatives showed PL emission maxima over a wider range of wavelengths, from 507-616 $\mathrm{nm}$. These compounds displayed significant differences in their electronic spectra due to the presence of electron-donating functional groups.

The results for the compounds I-IV are interesting because recently several compounds have been reported that exhibit a strong fluorescence in either the liquid or solid states. For organic molecules, aggregation is a common phenomenon that occurs in solution of high concentrations. However, one deleterious side effect of aggregation is the problem of emission quenching due to strong electronic interactions, hydrogen bonding or $\pi-\pi$ stacking (Xie, et al., 2005; Lamand \& Tang, 2005; Kraft, Grimsdale \& Holmes, 1998). Therefore, the compounds reported in the present paper are interesting emission properties similar to reported by Tang and coworkers. They recently observed a novel phenomenon that overcomes fluorescence quenching in aggregation, which they called aggregation-induced emission (AIE) (An, et al., 2002; Lim, et al., 2004). Molecules exhibiting emission behavior which depends on its aggregative state are of particular interest because the aggregation-dependent luminescence which can find applications in the fields of sensors or OLED.

\section{Conclusions}

$N, N$-Diphenylaminophenylpyridineacrylonitrile derivatives showed high fluorescence in the liquid as well as in the solid state. The compounds were prepared via the Knoevenagel procedure from the reaction of $\mathrm{N}, \mathrm{N}$-diphenylaminophenylbenzaldehyde and phenylacrylonitriles in the presence of piperidine as a catalyst. The intensities and positions of the emission bands in the newly synthesized compounds as well as their quantum yields 
could be related to the nature of the substituents on the structure, i. e., the - $\mathrm{CN}$ substituent on the vinylene moiety of the compound and the position of the $\mathrm{N}$ atom on the pyridine ring, but the interesting properties could also be caused by the high degree of conjugation conferred to the compounds by the $-\mathrm{N}(\mathrm{Ph})_{2}$ group. It is also interesting to note that compound III has an inherently higher fluorescence quantum yield in the solid state and that its fluorescence emission appears as a clear red shift. Given this, such systems may be regarded as potentially promising candidates for electroluminescent devices.

\section{References}

Adès, D., Boucard, V., Cloutet, E., Siove, A., Olivero, C., Castex, M. C., \& Pichler, G. (2000). Photoluminescence of donor-acceptor carbazole-based molecules in amorphous and powder forms. Journal of Applied Physics, 87, 7290-7293. http://dx.doi.org/10.1063/1.372982

An B. K., Kwon S. K., Jung, S. D., \& Park S. Y. (2002). Enhanced Emission and Its Switching in Fluorescent Organic Nanoparticles. Journal of American Chemical Society, 124, 14410-14415. http://dx.doi.org/10.1021/ja0269082

Cardinales, T., Lava, K., Goossens, K., Eliseeva, S. V., \& Binnemans, K. (2011). 1,10-Phenanthrolinium Ionic Liquid Crystals. Lagmuir, 27, 2036-2043. http://dx.doi.org/10.1021/la1047276

Chen, C. Y., Pootrakulchote, N., Wu, S. J., Wang, M., Li, J.-Y., Tsai, J. H., Wu, C. G., Zakeeruddin, S. M., \& Grätzel M. (2009). New ruthenium sensitizer with carbazole antennas for efficient and stable thin-film dye-sensitized solar cells. The Journal of Physical Chemistry C, 113, 20752-20757. http://dx.doi.org/10.1021/jp9089084

Chen, J. P., Tanabe, H., Li, X.-C., Thoms, T., Okamura, Y., \& Ueno, K. (2003). Novel organic hole transport material with very high $\mathrm{T}_{\mathrm{g}}$ for light-emitting diodes. Synthetic Metals, 132, 173-176. http://dx.doi.org/10.1016/S0379-6779(02)00203-5

Chow, T. J., Lin, R., Ko, C. H., \& Tao, Y. T. (2002). Photo and electroluminescence of 2-anilino-5-phenylpenta-2,4-dienenitrile derivatives. Journal of Materials Chemistry, 12, 42-46. http://dx.doi.org/10.1039/b103508h

Dailey, S., Halim, M., Rebourt, E., Hoursburgh, L. E., Samuel, I. D. W., \& Monkman, A. P. (1998). An efficient electron-transporting polymer for light-emitting diodes. Journal of Physics: Condensed Matter, 10, 5171-5178. http://dx.doi.org/10.1088/0953-8984/10/23/017

De Mello, J. C., Wittmann, H. F., \& Friend, R. H. (1997). An improved experimental determination of external photoluminescence quantum efficiency. Adv. Mater., 9, 230-232. http://dx.doi.org/10.1002/adma.19970090308

Ego, C., Grimsdale, A. C.; Uckert, F., Yu, G., Srdanov, G., \& Müllen, K. (2002). Triphenylamine-substituted polyfluorene a stable blue-emitter with improved charge injection for light-emitting diodes. Advanced Materials, 14, 809-811. http://dx.doi.org/10.1002/1521-4095(20020605)14:11<809::AID-ADMA809>3.0.CO;2-8

Epstein, A. J., Blatchford, J. W., Wang, Y. Z., Jessen, S. W., Gebler, D. D., Lin, L. B., Gustafson, T. L., Wang, H. L., Park, Y. W., Swager, T. M. A., \& MacDiarmind, G. (1996). Poly ( $p$-pyridine) - and poly ( $p$-pyridyl vinylene) -based polymers: their photophysics and application to SCALE devices. Synthetic Metals, 78, 253-261. http://dx.doi.org/10.1016/0379-6779(96)80147-0

Esteves, M. A., Narender, N., Marcelo-Curto, M. J., \& Gigante, B. (2001). Synthetic derivatives of abietic acid with radical scavenging activity. Journal of Natural Products, 64, 761-766. http://dx.doi.org/10.1021/np000501y

Friend, R. H., Gymer, R. W., Holmes, A. B., Burroughes, J. H., Marks, R. N., Taliani, C., Bradley, D. D. C., Dos Santos, D. A., Brédas, J. L., Löglund, M., \& Salaneck, W. R. (1999). Electroluminescence in conjugated polymers. Nature, 397, 121-128. http://dx.doi.org/10.1038/16393

Gondek, E., Danel, A., \& Kityk, I. V. (2008). Single-layered light-emitting diodes possessing methoxy-modified pyrazoloquinoline dyes in poly- $N$-vinylcarbazole matrix. Journal of Luminescence, 128, 348-354. http://dx.doi.org/10.1016/j.jlumin.2007.08.008

Gordon, A. J. \& Ford, R. A. (1972). The Chemist's Companion-A Handbook of Practical Data, Techniques, and References. John Wiley \& Sons, Inc.: Hoboken, NJ, USA.

Jiang, X. Z., Liu, S., Liu, M. S., Herguth, P., Jen, A. K.-Y., Fong, H., \& Sarikaya, M. (2002). Perfluorocyclobutane-based arylamine hole-transporting materials for organic and polymer light-emitting diodes. Advanced Functional Materials, 12, 745-751. http://dx.doi.org/10.1002/adfm.200290002 
Justin Thomas, K. R., Lin, J. T., Tao, Y.-T., \& Chuen, C. H. (2002). Electroluminescent bipolar compounds containing quinoxaline or pyridopyrazine and triarylamine segments. Journal of Materials Chemistry, 12, 3516-3522. http://dx.doi.org/10.1039/b206126k

Knoevenagel E. (1896). Ueber eine darstellungsweise des benzylidenacetessigesters. Berichte der Deutschen Chemischen Gesellschaft, 29, 172-174. http://dx.doi.org/10.1002/cber.18960290133

Kraft, A., Grimsdale, A. C., \& Holmes, A. B. (1998). Electroluminescent Conjugated Polymers-Seeing Polymers in a New Light. Angewandte Chemie International Edition, 37, 402-428. http://dx.doi.org/10.1002/(SICI)1521-3773(19980302)37:4<402::AID-ANIE402>3.0.CO;2-9

Lamand, J. W. Y., \& Tang, B. Z. (2005). Functional Polyacetylenes. Accounts of Chemical Research, 38, 745-754. http://dx.doi.org/10.1021/ar040012f

Lim S. J., An B. K., Jung S. D., Chung M. A., \& Park S. Y. (2004). Photoswitchable Organic Nanoparticles and a Polymer Film Employing Multifunctional Molecules with Enhanced Fluorescence Emission and Bistable Photochromism. Angewandte Chemie International Edition, 43, 6346-6350. http://dx.doi.org/10.1002/anie.200461172

Loy, D. E., Koene, B. E., \& Thompson, M. E. (2002). Thermally stable hole-transporting materials based upon a

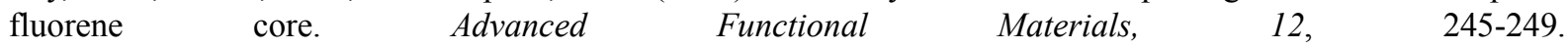
http://dx.doi.org/10.1002/1616-3028(20020418)12:4<245::AID-ADFM245>3.0.CO;2-5

Miteva, T., Meisel, A., Knoll, W., Nothofer, H. G., Scherf, U., Müller, D. C., Meerholz, K., Yasuda, A., \& Neher, D. (2001). Improving the performance of polyfluorene-based organic light-emitting diodes via end-capping. Advanced Materials, 565-570. http://dx.doi.org/10.1002/1521-4095(200104)13:8<565::AID-ADMA565>3.0.CO;2-W

Naito, K., \& Miura, A. (1993). Molecular design for nonpolymieric organic dye glasses with thermal stability: relations between thermodynamic parameters and amorphous properties. The Journal of Physical Chemistry, 97, 6240-6248. http://dx.doi.org/10.1021/j100125a025

Ning, Z., \& Tian, H. (2009). Triarylamine: a promising core unit for efficient photovoltaic materials. Chemical Communications, 37, 5483-5495. http://dx.doi.org/10.1039/b908802d

Okutsu, S., Onikubo, T., Tamano, M., \& Enokida, T. (1997). Molecular design of hole transport material with various ionization potential for organic light-emitting diode applications. IEEE Transactions on Electron Devices, 44, 1302-1306. http://dx.doi.org/10.1109/16.605472

Pai, D. M., Yanus, J. F., \& Stolka, M. (1984). Trap-controlled hopping transport. The Journal of Physical Chemistry, 88, 4714-4717. http://dx.doi.org/10.1021/j150664a054

Patra, A., Pan, M., Friend, C. S., Lin, T.-Ch., Cartwright, A. N., \& Prasad, P. N. (2002). Electroluminescence properties of systematically derivatized organic chromophores containing electron donor and acceptor groups. Chemistry of Materials, 14, 4044-4048. http://dx.doi.org/10.1021/cm020075x

Percino, M. J., Chapela, V. M., Montiel, L.-F., \& Rodríguez-Babarín, C. (2008). X-Ray crystal structures of a 1-(p-fluorophenyl)-2-( $\alpha$-pyridyl)ethanol intermediate and the 1-( $p$-fluorophenyl)-2-( $\alpha$-pyridyl)ethane dehydration compound obtained from the condensation reaction of 2-methylpyridine and $p$-fluorobenzaldehyde. The Open Crystallography Journal, 1, 37-41. http://dx.doi.org/10.2174/1874846500801010037

Percino, M. J., Chapela, V. M., Montiel, L.-F.; Pérez-Gutiérrez, E., \& Maldonado-Rivera, J. L. (2010). Spectroscopic characterization of halogen- and cyano-substituted pyridinevinylenes synthesized without catalyst or solvent. Chemical Papers, 64, 360-367. http://dx.doi.org/10.2478/s11696-010-0012-z

Percino, M. J., Chapela, V. M., Pérez-Gutiérrez, E., Cerón, M., \& Soriano, G. (2011). Synthesis, optical, and spectroscopic characterisation of substituted 3-phenyl-2-arylacrylonitriles. Chemical Papers, 65, 42-51. http://dx.doi.org/10.2478/s11696-010-0075-x

Percino, M. J., Chapela, V. M., Sanchez, A., \& Maldonado-Rivera, J. L. (2006). Condensation reactions of methylpyridines and aromatic aldehydes under catalyst and solvent free Conditions. The chemistry: An Indian Journal, 3, 262-267.

Percino, M. J., Chapela, V. M., Urzúa, O., Montiel, L.-F. \& Rodríguez-Barbarín, C. (2007). 1-(p-Fluorophenyl)-2-(2'-pyridyl)ethanol and 1-(p-fluorophenyl)-2-(2'-pyridyl)ethene obtained from the condensation reaction of 2-picoline and $p$-fluorophenylaldehyde under catalyst- and solvent-free conditions. Research on Chemical Intermediates, 33, 623-629. 
Pérez-Gutiérrez, E., Percino, M. J., Chapela, V. M., Cerón, M., Maldonado-Rivera, J. L., \& Ramos-Ortíz, G. (2011). Synthesis, characterization and photophysical properties of pyridine-carbazole acrylonitrile derivatives. Materials, 4, 562-574. http://dx.doi.org/10.3390/ma4030562

Pond, S. J. K., Rumi, M., Levin, M. D., Parker, T. C., Beljonne, D., Day, M. W., Brédas, J.-L., Marder, S. R., \& Perry, J. W. (2002). One- and two-photon spectroscopy of donor-acceptor-donor distyrylbenzene derivatives: effect of cyano substitution and distortion from planarity. The Journal of Physical Chemistry A, 106, 11470-11480. http://dx.doi.org/10.1021/jp0267104

Redecker, M., Bradley, D. D. C., Inbasekaran, M., Wu, W. W., \& Woo, E. P. (1999). High mobility hole transport fluorene-triarylamine copolymers. Advanced $\quad$ Materials, $11, \quad$ 241-246. http://dx.doi.org/10.1002/(SICI)1521-4095(199903)11:3<241::AID-ADMA241>3.0.CO;2-J

Salbeck, J. (1996). Electroluminescence with organic compounds. Ber. Bunsenges. Phys. Chem., 100, 1667-1677.

Samuel, I. D. W., \& Turnbull, G. A. (2007). Organic semiconductor lasers. Chemical Reviews, 107, 1272-1295. http://dx.doi.org/10.1021/cr050152i

Satoh, N., Cho, J.-S., Higuchi, M., \& Yamamoto, K. (2003). Novel triarylamine dendrimers as a hole-transport material with a controlled metal-assembling function. Journal of American Chemical Society, 125, 8104-8105. http://dx.doi.org/10.1021/ja034811p

Shaheen, E. S., Brabec, C. J., Sariciftci, N. S., Padinger, F., Fromherz, T., \& Hummelen, J. C. (2001). 2.5\% efficient organic plastic solar cells. Applied Physics Letters, 78, 841-843. http://dx.doi.org/10.1063/1.1345834

Strohriegl, P., \& Grazulevicius, J. V. (2002). Charge-transporting molecular glasses. Advanced Materials, 14, 1439-1452. http://dx.doi.org/10.1002/1521-4095(20021016)14:20<1439::AID-ADMA1439>3.0.CO;2-H

Strzelec, K., Tsukamoto, N., Kook, H. J., \& Sato, H. (2001). Synthesis and characterization of new 4-tolyldiphenylamine derivatives for hole transporting polymers. Polymer International, 50, 1228-1233. http://dx.doi.org/10.1002/pi.770

Tessler, N., Denton, G. J., \& Friend, R. H. (1996). Lasing from conjugated-polymer microcavities. Nature, 382, 695-697. http://dx.doi.org/10.1038/382695a0

Thelakkat, M., Schmitz, C., Hohle, C., Strohriegl, P., Schmidt, H.-W., Hofmann, U., Schloter, S., \& Haarer, D. (1999). Novel functional materials based on triarylamines-synthesis and application in electroluminescent devices and photorefractive systems. Physical Chemistry Chemical Physics, 1, 1693-1698. http://dx.doi.org/10.1039/a808618d

Tong, K. L., So, S. K., Ng, H. F., Leung, L. M., Yeung, M. Y., \& Lo, C. F. (2004). Transport and luminescence in nathphyl phenylamine complexes. Synthetic Metals, 147, 199-203. http://dx.doi.org/10.1016/j.synthmet.2004.06.036

Tong, Y., Wu, Z., Yang, C., Yu, J., Zhang, X., Yang, S., Deng, X., Xu, Y., \& Wen, Y. (2001). Determination of diphenylamine stabilizer and its nitrated derivatives in smokeless gunpowder using a tandem MS method. Analyst, 126, 480-484. http://dx.doi.org/10.1039/b010183o

Wang, B., Wang, Y., Hua, J., Jiang, Y., Huang, J., Qian, S., \& Tian, H. (2011). Starburst triarylamine donor-acceptor-donor quadrupolar derivatives based on cyano-substituted diphenylaminestyrylbenzene: tunable aggregation-induced emission colors and large two-photon absorption cross sections. Chemistry-A European Journal, 17, 2647-2655. http://dx.doi.org/10.1002/chem.201002821

Williams, D. H. \& Fleming, I. (1980). Spectroscopic Methods in Organic Chemistry, 3rd ed. McGraw-Hill: Maidenhead, UK.

Xie, Z., Yang, B., Li, F., Cheng, G., Liu, L., Yang, G.., Xu, H., Ye, L., Hanif, M., Liu, S., Ma, D., \& Ma, Y. (2005). Cross Dipole Stacking in the Crystal of Distyrylbenzene Derivative: The Approach toward High Solid-State Luminescence Efficiency. Journal of American Chemical Society, 127, 14152-14153. http://dx.doi.org/10.1021/ja054661d

Xin, H., Guang, M., Li, F. Y., Bian, Z. Q., Huang, C. H., Ibrahim, K., \& Liu, F. Q. (2002). Photoluminescence and electroluminescence of the exciplex formed between a terbium ternary complex and $N, N$ '-diphenyl- $N, N$ '-bis(3-methylphenyl)-1,1'-diphenyl-4,4'-diamine. Physical Chemistry Chemical Physics, 4, 5895-5898. http://dx.doi.org/10.1039/b207990a 
Yakushchenko, I. K., Kaplunov, M. G., Efimov, O. N., Yu Belov, M., \& Shamaev, S. N. (1999) Polytryphenylamine derivatives as materials for hole transporting layers in electroluminescent devices. Physical Chemistry Chemical Physics, 1, 1783-1785. http://dx.doi.org/10.1039/A808613C

Yang, J.-S., Chiou, S.-Y., \& Liau, K. L. (2002). Fluorescence enhancement of trans-4-aminostilbene by $N$-phenyl substitutions: the "amino conjugation effect". Journal of American Chemical Society, 124, 2518-2527. http://dx.doi.org/10.1021/ja016416

Yu, G., Gao. J., Hummelen, J. C., Wudl, F., \& Heeger, A. J. (1995). Polymer photovoltaic cells: Enhanced efficiencies via a network of internal donor-acceptor heterojunctions. Science, 270, 1789-1791. http://dx.doi.org/10.1126/science.270.5243.1789

Zhang, X.-H., Wang, Z.-S., Cui, Y., Koumura, N., Furube, A., \& Hara, K. (2009). Organic sensitizers based on hexylthiophene-functionalized indolo[3,2-b]carbazole for efficient dye-sensitized solar cells. The Journal of Physical Chemistry C, 113, 13409-13415. http://dx.doi.org/10.1021/jp808536v

Zhou, Y., Xiao, Y., Chi, S., \& Qian, X. (2008). Isomeric boron-fluorine complexes with donor-acceptor architecture: Strong solid/liquid fluorescence and large stokes shift. Organic Letters, 10, 633-636. http://dx.doi.org/10.1021/ol702963w

Table 1. Conditions, yields and properties of the compounds shown in Scheme 1

\begin{tabular}{|c|c|c|c|c|c|c|}
\hline Compound & $\begin{array}{c}\text { Temp. } \\
{ }^{\circ} \mathrm{C}\end{array}$ & $\underset{\mathrm{h}}{\mathrm{Time}}$ & $\begin{array}{l}\text { Yield } \\
\%\end{array}$ & Appearance & $\begin{array}{l}\text { Melting point } \\
{ }^{\circ} \mathrm{C}\end{array}$ & Solubility \\
\hline I & 100 & 36 & 42 & $\begin{array}{l}\text { Yellow } \\
\text { powder }\end{array}$ & $162-164$ & $\begin{array}{l}\text { Toluene, } \mathrm{CHCl}_{3}, \mathrm{THF}, \\
\text { EtOH, } \mathrm{MeOH}, \mathrm{Me}_{2} \mathrm{CO} \text {, } \\
\text { DMSO, ethyl acetate. }\end{array}$ \\
\hline II & 100 & 24 & 32 & $\begin{array}{l}\text { Yellow-orange } \\
\text { powder }\end{array}$ & $142-144$ & $\begin{array}{c}\mathrm{CHCl}_{3}, \mathrm{THF}, \mathrm{C}_{6} \mathrm{H}_{5} \mathrm{OH} \\
\mathrm{Me}_{2} \mathrm{CO}, \mathrm{MeOH}, \mathrm{DMSO}\end{array}$ \\
\hline III & 100 & 36 & 19 & Yellow powder & $108-110$ & $\begin{array}{l}\mathrm{CHCl}_{3}, \mathrm{THF}, \mathrm{Me}_{2} \mathrm{CO} \\
\text { EtOH, } \mathrm{MeOH}, \mathrm{DMSO}\end{array}$ \\
\hline IV & 100 & 34 & 31 & Orange powder & $153-155$ & $\begin{array}{c}\mathrm{CHCl}_{3}, \mathrm{THF}, \mathrm{Me}_{2} \mathrm{CO} \text {, } \\
\text { acetone, EtOH, MeOH, } \\
\text { DMSO }\end{array}$ \\
\hline
\end{tabular}


Table 2. Spectral characterization of the compounds I-IV in Scheme 1

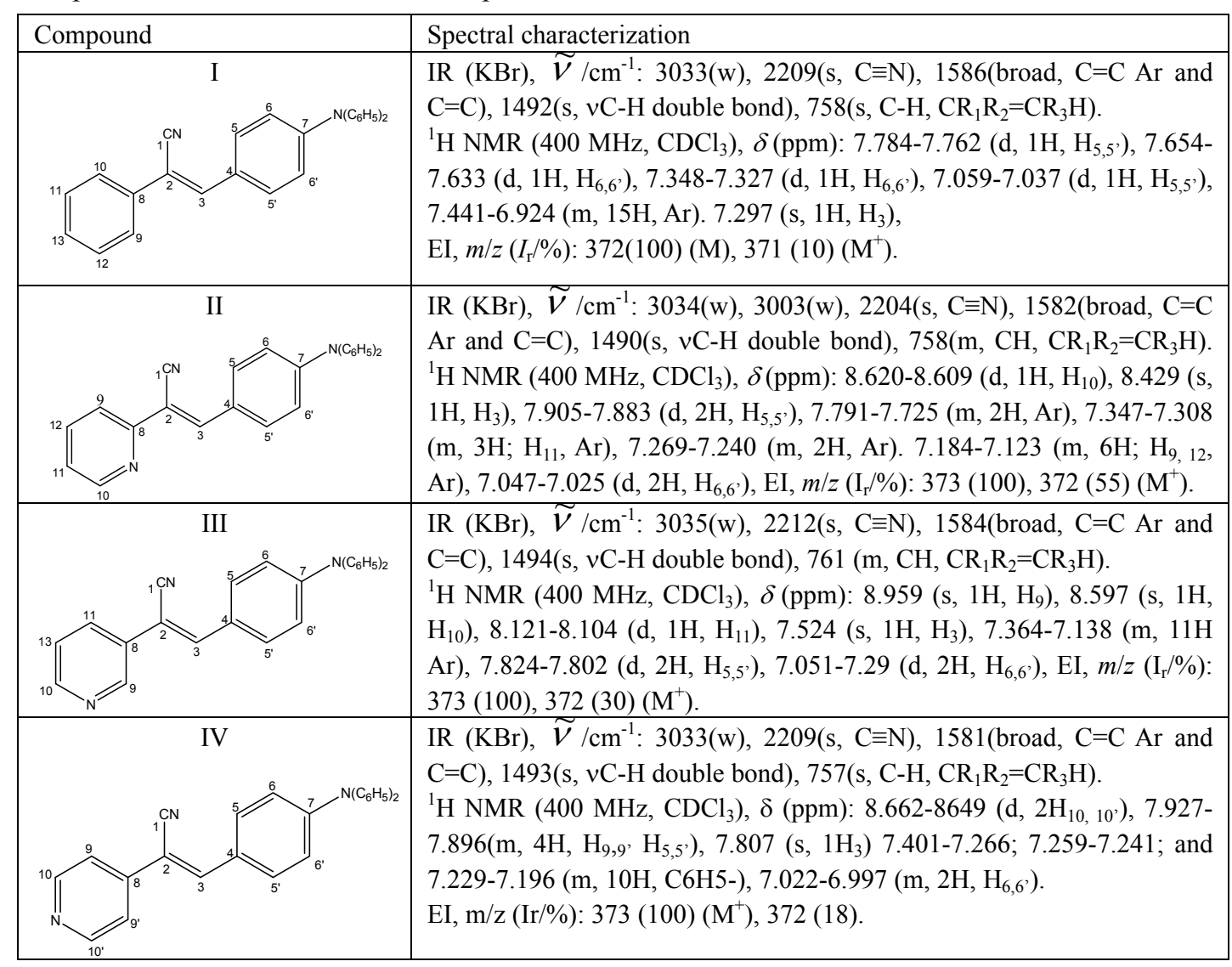<smiles>Cc1ccccc1CCc1ccc(N(c2ccccc2)c2ccccc2)cc1</smiles><smiles>N#C/C(=C\c1ccc(N(c2ccccc2)c2ccccc2)cc1)c1ccccc1</smiles>

Scheme 1. Synthesis of 2-(phenyl)-3-(4-diphenylaminophenyl)acrylonitrile (I),

2-(2'-pyridyl)-3-(4-diphenylaminophenyl)acrylonitrile (II),

2-(3'-pyridyl)-3-(4-diphenylamino-phenyl)acrylonitrile (III) and 2-(4' -pyridyl)-3-(4diphenylaminophenyl)acrylonitrile (IV) 


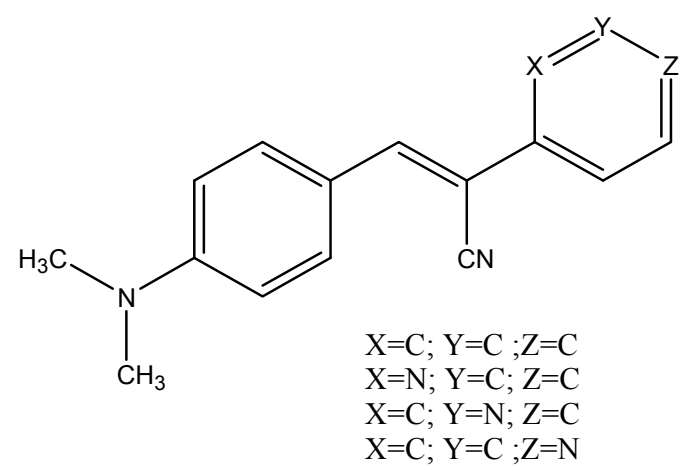

Scheme 2. $N, N$-Dimethylaminophenylcrylonitriles derivatives (from ref. 46)
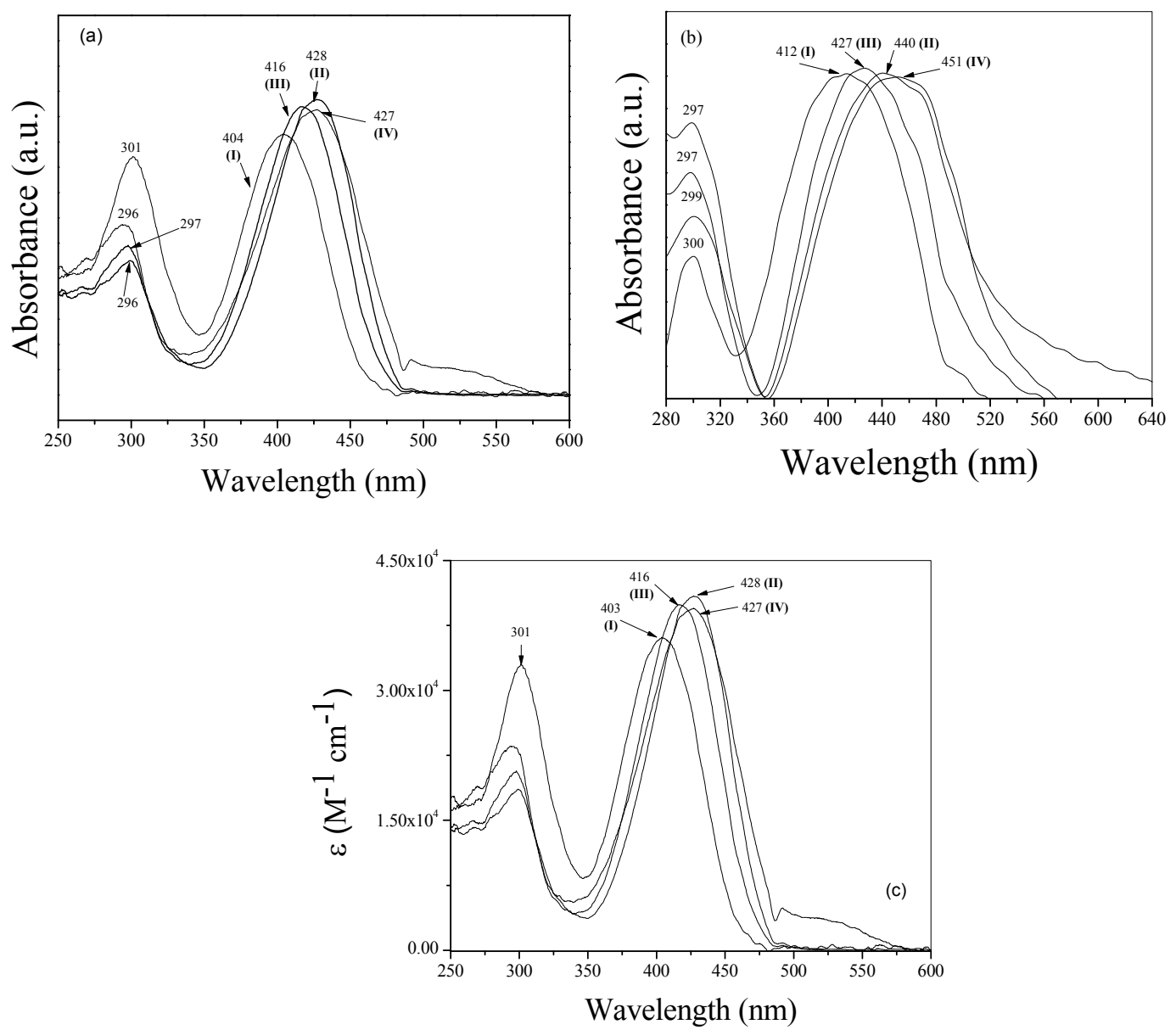

Figure 1. Absorbance spectra of compounds I-IV in (a) $\mathrm{CHCl}_{3}$ and (b) solid state (KBr) as well as (c) the molar absorptivity values $(\varepsilon)$ of the compounds 

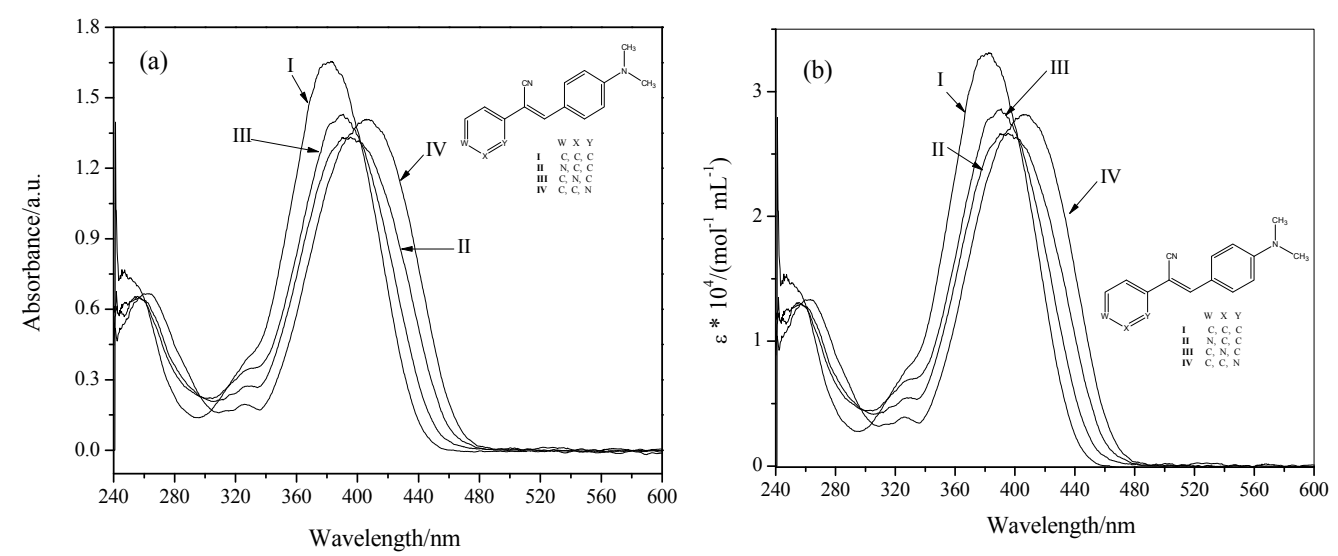

Figure 2. Absorbance (a) and molar absorptivity $\varepsilon$ (b) of pheny, ortho, meta and para compounds synthesized with the $-\mathrm{N}\left(\mathrm{CH}_{3}\right)_{2}$ substituent in $\mathrm{CHCl}_{3}$ (from ref. 46)

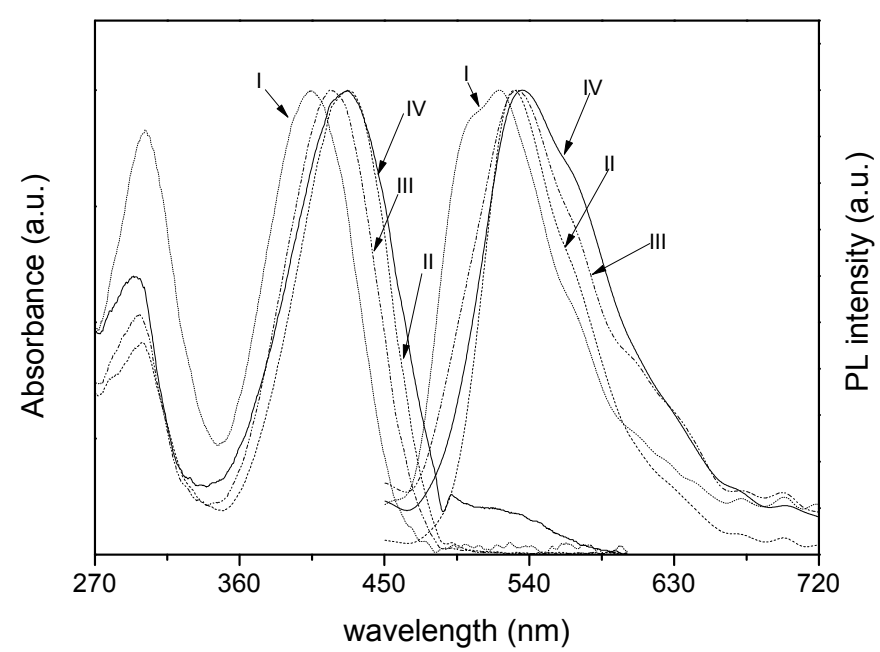

Figure 3. Absorbance and luminescence emission for the compounds I-IV in chloroform solution. I (....), II (- - $-)$, III (- - - ), and IV (-)
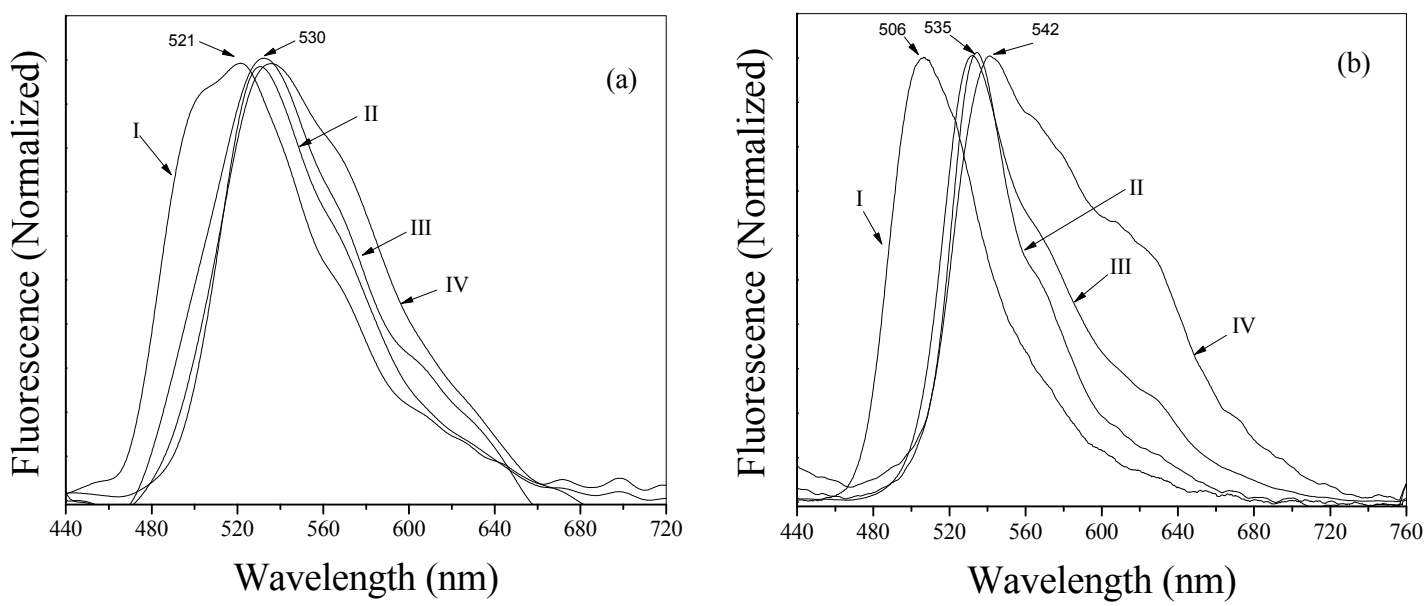

Figure 4. PL emissions of compounds $\mathbf{I}-\mathbf{I V}$ in (a) $\mathrm{CH}_{3} \mathrm{Cl}$ and (b) in solid state. Excitation wavelength for both conditions was $368 \mathrm{~nm}$ 


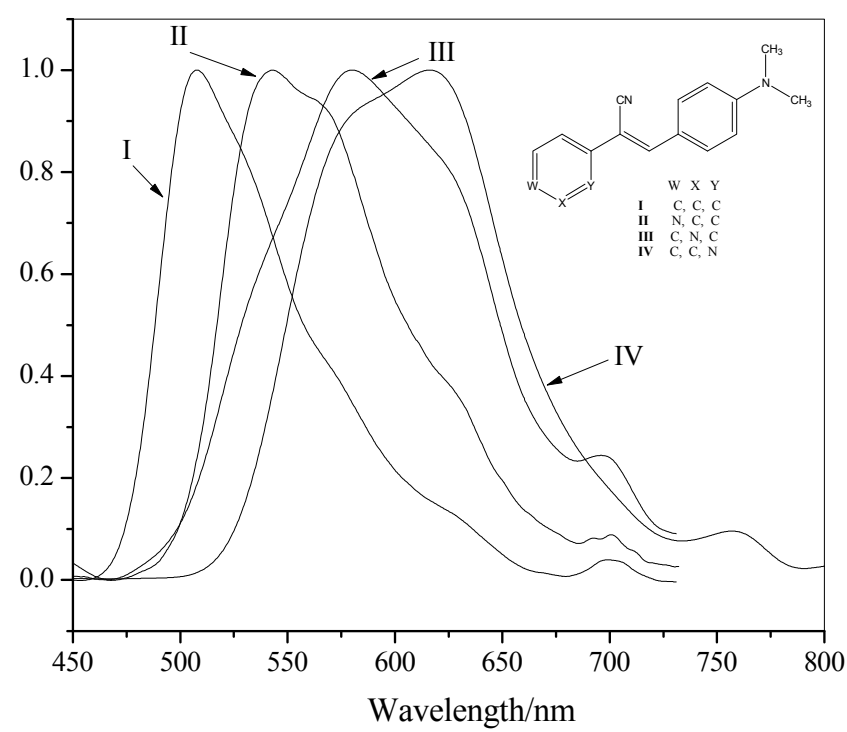

Figure 5. PL emission of previously reported compounds containing - $\mathrm{N}\left(\mathrm{CH}_{3}\right)_{2}$ substituents (from ref. 46 in solid state. Excitation wavelength in the studies was $368 \mathrm{~nm}$ 